\title{
A Brief Review on Robotic Exoskeletons for Upper Extremity Rehabilitation to Find the Gap between Research Porotype and Commercial Type
}

\author{
Md Rasedul Islam*, Christopher Spiewak, Mohammad Habibur Rahman and Raouf Fareh
}

College of Engineering and Applied Science, University of Wisconsin-Milwaukee, USA

\begin{abstract}
The number of disabled individuals due to stroke is increasing day by day and is projected to continue increasing at an alarming rate in United States. But the current amount of health professionals in physical therapy is inadequate to provide rehabilitation to these large groups. From early 1990s, researchers have been trying to develop an easy and feasible solution to this problem and lot of assistive devices both end effector type or exoskeleton type have been developed till to date. However, only a few of them have been commercialized and are being used in rehabilitation of post-stroke patients. Making the use of exoskeletons and other devices to regain lost motor function is rare. Providing therapy to this large group is quite impossible without commercializing of exoskeleton. This has motivated the authors to make a literature review and figure the reasons out that need to be solved to bridge the gap between research prototype to commercial version. This paper covers the necessity of incorporating robotic devices in rehabilitation, a brief description of existing devices particularly upper limb exoskeletons, their hardware limitations, and control issues. Our review shows that there are significant flaws in hardware design and developing control algorithm of exoskeletons to be available in rehabilitation program.
\end{abstract}

Keywords: Stroke, Rehabilitation, Exoskeleton, Upperlimb, Hardware, Control

\section{Introduction}

American heart association reports, approximately 785,000 persons experienced a new or recurrent cerebral vascular accident (CVA) or stroke annually in the United States among which number of deaths estimated at 58000 [1]. Stroke is a leading cause of serious long-term disability in the United States. The number of people living with stroke is projected to increase by 4 million by 2030 in the USA [2]. Hemiparesis/hemiplegia is the most common outcome of stroke (which leads to movement deficiency in the contralateral limbs to the side of the brain affected by the stroke) causes of losing arm motor function [3].

A large number of survivors following a stroke experience a disability like impaired upper limb resulted by loss of partial or full mobility. In addition, motor function of human upper limb can be lost due to sports injuries, trauma, occupational injuries, and spinal cord injuries [4-6]. Moreover, physical disabilities such as full or partial loss of function in the shoulder, elbow or wrist are a common impairment in the elderly people. This impairment yields several impacts on domestic life, social life as well as economy of the country. For instance, every year the total cost from lost future productivity is $\$ 124.5$ billion in United States due to stroke [7]. Therefore, it is essential to restore motor function in order to perform activities of daily living (ADL) and return those individuals as early as possible into their domestic and social life, and to save revenue from being lost as well.

The recovery is partial in stroke survivors, with $15 \%-30 \%$ of patients permanently disabled and $20 \%$ requiring institutional care at 3 months after onset [8]. Although there are several approaches, extensive task specific repetitive movement is one of the safe and effective method to regain lost mobility of the upper limb. The individuals those got a stroke, require incessant medical care and intensive rehabilitation often requiring one-on-one manual interaction with the physical therapist
[3]. However, present demands and budget restrictions makes the duration of rehabilitation program shorter.

Moreover, robotic devices have the potentiality of being used in providing therapy for a long period of time irrespective of skills and fatigue compared to manual therapy [9]. These emphasize the incorporation of robotic devices in rehabilitation therapy of post-stroke patients. Also, robotic devices can work in multi degrees of freedom with virtual reality interface and provide therapy ranging from passive to active rehabilitation. Thus integration of robotic therapy into current practice could increase the efficiency and effectiveness of therapists by alleviating the labor-intensive aspects of physical rehabilitation [10]. Furthermore previous literature advocates that robot-assisted rehabilitation in post-stroke individuals have advantages in terms of clinical and biomechanical measures to regain arm motor function in comparison with conventional treatment [10-16]. Indeed performing repetitive movements with the affected limb of the post-stroke patient obtain functional gain thereby an increase of motivation which helps to use arm further [17-20].

The robotic devices had been incorporated in physical therapy and rehabilitation program for stroke patients from two decades ago [21]. From then, researchers have developed devices both end effector type and exoskeleton type to use in rehabilitation of affected upper limb. But

*Corresponding author: Md Rasedul Islam, College of Engineering and Applied Science, University of Wisconsin-Milwaukee, WI 53211, USA, Tel: 14142291122 E-mail: islam4@uwm.edu

Received October 27, 2017, Accepted November 13, 2017, Published November 20, 2017

Citation: Islam MR, Spiewak C, Rahman MH, Fareh R (2017) A Brief Review on Robotic Exoskeletons for Upper Extremity Rehabilitation to Find the Gap between Research Porotype and Commercial Type. Adv Robot Autom 6: 177. doi: 10.4172/2168-9695.1000177

Copyright: (C) 2017 Islam MR, et al. This is an open-access article distributed under the terms of the Creative Commons Attribution License, which permits unrestricted use, distribution, and reproduction in any medium, provided the original author and source are credited. 
there are a few which is being used for rehabilitation program and are commercially available. To provide rehabilitation training to the large group of patients necessitates the essentiality of commercial success of these robotic devices.

In this treatise, a review was done to figure out the reasons and shortcomings that refrain upper limb exoskeletons from being used and gaining commercial success. Though many reviews on upper limb exoskeletons, but there still lack of sufficient information. For example, Jarrassé et al. [22] review include actuation, DOF, clinical study but not control method, portability, modes of therapy etc. whereas, Maciejasz et al. [23] lack review about modes of therapy. The authors want to make a complete and brief review including as much as information so that the new researchers who are going to work can have useful and valuable information at a glance. The ongoing review has particularly focused on the exoskeletons for upper limb although some other devices like end effector based type and some power assistance device to perform ADL were summarized in Table 1. The main focus of the review was why research porotype of exoskeleton did not turn itself to commercial version. This paper contains five sections. The information about various robotic devices that has been developed so far would be appeared in section-II while section-II is all about hardware issues. In section-IV, control issues need to be solved would be discussed. The section V and VI would be discussion and conclusion.

\section{Past Works}

The use of robotic devices in upper limb rehabilitation is seen to have started in the early 1990s [21]. From then, many research groups have developed robotic devices for rehabilitation of stroke patients who lost their arm motor function. In this paper, authors have made an extensive review on those devices to date. These rehabilitation robotic devices for upper limb can be classified depending on the limb is going to be connected with them. First, end-effector type - the upper limb is attached with only end-effector of the robotic device. Second, exoskeleton type - the upper limb has not only attachment with end effector but also more point of contact. Although both end effector type and exoskeleton type robotic devices has been summarized in Table 1, the upper limb exoskeletons were the focus during the study. However, the first column in table mention the name of the device or researcher who developed it whereas the second column goes for types. In this study, robotic devices are categorized based on five criteria. Firstly, end-effector type (Figure 1) or exoskeleton type (Figure 2). Secondly,

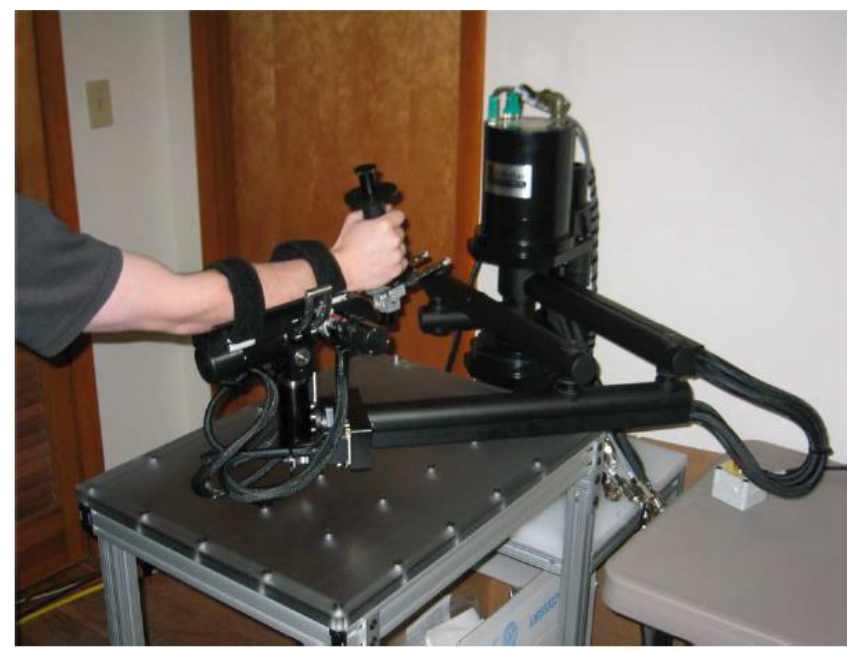

Figure 1: End effector type device (Inmotion Wrist [24]). robotic devices are categorized based on purpose of use of the device either it can be used for rehabilitation (Figure 3), power assistance (Figure 4) to perform ADL or both (Figure 5). The third one shows the type of actuation whereas fourth type indicates the training mode of the device. The unilateral mode involves only the movement of affected limb while bilateral mode requires the simultaneous movement of both affected and unaffected limb in similar fashion. The last category is based on the portability of the device. If it is attached to a fixed point which cannot be shifted or moved is termed as grounded. Otherwise device is ungrounded. The degrees of freedom are shown in third column whereas fourth column depicts the scope of movement of upper limb. The fifth column simply reveals the control approach that was used in the device. However, sixth column mention the therapy mode which needs to be explained. Primarily, the rehabilitation therapy could be categorized as active mode and passive mode. Further active mode might be classified as active resist and active assist [25-29]. In active assist, patient contributes in motion achievement partially but in active resistance mode, hindrance is provided to the following of predefined trajectory. In passive mode, no contribution from the patient's side to move along the predefined path. The last column in the table says about clinical test of the device. This is what really need to increase the use of robotic devices in rehabilitation therapy.

\section{Hardware Issues}

The early robotic assistive devices e.g., MIT Manus now In Motion [24], MIME [10] are end-effector type, most of which were built based on planar motion. The end effector type devices are simple in structure, easily adjustable as it is attached to only one point of patient's limb during therapy, low cost compared to exoskeletons [29]. But they are limited to mimic the motion of upper limb's different joints, making difficult to measure torque at limb's joints. On the other hand, exoskeletons, which have been developed during mid-2000s can depict the motion of human upper limb and therefore are more suitable at producing joint trajectories with necessary torques. The hardware of exoskeletons is more complex, heavy and requiring attention to match the natural redundancy to make sure proper joint alignment with the human anatomy. The early robotic exoskeletons for upper limb rehabilitation lacked sophistication in hardware structure and design. Some research groups have redesigned, remodeled and built updated version of what they had developed first. For example, ARMIN III [92] is successor of ARMIN-I [91], LIMPACT [71] successor of DAMPACE [67], MAHI Exo II [76,77] successor of MAHI Exo [84]. In later versions, they have done apparent modification to make the hardware soft, more functional and good-looking. Despite development of many exoskeletons, there are a few exoskeletons available in the market for post-stroke patient's upper limb rehabilitation hitherto though. The first commercial upper limb exoskeleton for rehabilitation i.e., Armin was introduced at $2011[22,113]$. By the way, the ground floor hardware issues that needs to be solved to make exoskeletons nobler would be discussed in this section.

\section{Joint alignment with human anatomy}

The anatomical structure of human upper limb is very complex and flexible. The instantaneous centres of rotation (ICR) at elbow and shoulder joints change with the joint motion [114]. The complexity of interaction between exoskeleton structure and human body is a major issue that requires attention. The incorrect alignment between exoskeleton and human upper limb makes patients uncomfortable when they are given therapy [115-119]. The intensity of uncomforting caused by tissue depression varies from annoying to pain depending 
Citation: Islam MR, Spiewak C, Rahman MH, Fareh R (2017) A Brief Review on Robotic Exoskeletons for Upper Extremity Rehabilitation to Find the Gap between Research Porotype and Commercial Type. Adv Robot Autom 6: 177. doi: 10.4172/2168-9695.1000177

Table 1: Robotic devices for upper limb rehabilitation of post stroke patients.

\begin{tabular}{|c|c|c|c|c|c|c|}
\hline Name/developer & Type & Active DOF & Scope of movements & Control approach & Modes of Operation & Clinical Test \\
\hline Bi-Manu-Track [30] & eef,R e,UB,G & 1 & $\begin{array}{l}\text { Forearm P/S, } \\
\text { Wrist F/E }\end{array}$ & IC & $\begin{array}{l}\text { Passive assist, } \\
\text { active assist and resist }\end{array}$ & Yes (12) \\
\hline Kung [31] & exo,R,e,U,G & 1 & Forearm P/S & FC & $\begin{array}{l}\text { Active assist } \\
\text { Passive assist }\end{array}$ & No \\
\hline Colombo [32] & eef,R,e,U,G & 1 & Wrist F/E & $\mathrm{AC}$ & Active assist & Yes (8) \\
\hline Song [33] & exo,R,e,U,G & 1 & Wrist F/E & PID, EMG & Active assist & Yes (5) \\
\hline $\mathrm{Hu}[34]$ & eef,R,e,U,G & 1 & Wrist F/E & EMG & Active assist & Yes (15) \\
\hline Pylatiuk [35] & exo,R,h,U,UG & 1 & Elbow F/E & EMG & Active assist & No \\
\hline Kiguchi [36] & exo,R,e,U,G & 1 & Elbow F/E & EMG & Active assist & No \\
\hline Cheng [37] & exo,R,e,U,G & 1 & Elbow F/E & EMG & Active assist & Yes (5) \\
\hline MARIONET [38] & eef,R,e,U,G & 1 & Elbow F/E & PC & Active assist & No \\
\hline Beigzadeh [39] & exo,R,e,U,G & 1 & Elbow F/E & EMG & Active assist & No \\
\hline Hosseini [40] & exo,R,e,U,G & 1 & Elbow F/E & EMG & Active assist & No \\
\hline Jarrett and McDaid [41] & exo,R,e,U,G & 1 & Elbow F/E & PD, SMC & Active assist & No \\
\hline ASSIST [42] & Exo,PA,p,U,UG & 1 & Wrist F/E & EMG & Active assist & No \\
\hline Papadopoulos [43] & exo,RP,e,U,UG & 2 & $\begin{array}{l}\text { Shoulder A/A } \\
\text { Shoulder F/E }\end{array}$ & ---------- & Active assist & No \\
\hline Freeman [44] & eef,R,e,U,G & 2 & $\begin{array}{l}\text { Planar movement of } \\
\text { forearm }\end{array}$ & IC & Active assist & No \\
\hline BFIAMT [45] & eef,R,e,B,G & 2 & $\begin{array}{l}\text { Axial movement of } \\
\text { forearm }\end{array}$ & PC & $\begin{array}{l}\text { Active assist } \\
\text { Passive assist }\end{array}$ & Yes (20) \\
\hline Kiguchi[36] & exo,PA,e,U,G & 2 & $\begin{array}{l}\text { Shoulder A/A } \\
\text { Shoulder F/E }\end{array}$ & EMG & Active assist & No \\
\hline Rosen [46] & Exo,PA,e,U,G & 2 & $\begin{array}{l}\text { Shoulder F/E } \\
\text { Elbow F/E }\end{array}$ & EMG & Active assist & No \\
\hline Khan [47] & exo,RP,e,U,UG & 2 & $\begin{array}{l}\text { Shoulder F/E } \\
\text { Elbow F/E }\end{array}$ & EMG & Active assist & No \\
\hline Triwiyanto [48] & exo,R,e,UB,G & 2 & $\begin{array}{l}\text { Shoulder F/E } \\
\text { Elbow F/E }\end{array}$ & EMG & Active assist & No \\
\hline ARM Guide [49] & eef,R,e,U,G & 3 & $\begin{array}{l}\text { Axial, elevation and } \\
\text { yaw of forearm }\end{array}$ & |---------- & $\begin{array}{l}\text { Active assist } \\
\text { Passive assist } \\
\text { resist }\end{array}$ & Yes (19) \\
\hline Kiguchi [50] & exo,PA,e,U,UG & 3 & $\begin{array}{l}\text { Shoulder A/A } \\
\text { Shoulder F/E } \\
\text { Elbow F/E }\end{array}$ & EMG & Active assist & No \\
\hline NeReBot [51] & eef,R,e,U,G & 3 & $\begin{array}{l}\text { Spatial movement of } \\
\text { shoulder and elbow }\end{array}$ & PID & $\begin{array}{l}\text { Active assist } \\
\text { Passive assist }\end{array}$ & Yes (24) \\
\hline CRAMER [52] & exo,R,p,U,G & 3 & $\begin{array}{l}\text { Forearm P/S, } \\
\text { Wrist F/E } \\
\text { Wrist R/U }\end{array}$ & PCM & Active assist & No \\
\hline InMotion WRIST [24] & eef,R,e,U,G & 3 & $\begin{array}{l}\text { Forearm P/S, } \\
\text { Wrist F/E } \\
\text { Wrist R/U }\end{array}$ & IC & $\begin{array}{l}\text { Active assist } \\
\text { Passive assist } \\
\text { resist }\end{array}$ & Yes (36) \\
\hline Takaiwa [53] & eef,R,p,U,G & 3 & $\begin{array}{l}\text { Forearm P/S, } \\
\text { Wrist F/E } \\
\text { Wrist R/U }\end{array}$ & IC & Active assist & No \\
\hline WOTAS $[54,55]$ & exo,R,e,U,UG & 3 & $\begin{array}{l}\text { Elbow F/E } \\
\text { Forearm P/S, } \\
\text { Wrist F/E }\end{array}$ & IC & resist & Yes (10) \\
\hline Rosales [56] & exo,R,e,U,UG & 3 & $\begin{array}{l}\text { Shoulder A/A } \\
\text { Shoulder F/E } \\
\text { Shoulder R }\end{array}$ & ---------- & $\begin{array}{l}\text { Active assist } \\
\text { Passive assist }\end{array}$ & No \\
\hline Mahdavian [57] & exo,R e,U,G & 3 & $\begin{array}{l}\text { Shoulder F/E, A/A, } \\
\text { Elbow F/E }\end{array}$ & IC & Passive assist & No \\
\hline Sharma and Ordonez [58] & exo,R e,U,G & 3 & $\begin{array}{l}\text { Shoulder F/E, } \\
\text { Elbow F/E } \\
\text { Forearm P/S, }\end{array}$ & PID & Passive assist & No \\
\hline ULEL [59] & exo,R e,U,G & 3 & $\begin{array}{l}\text { Shoulder F/E, } \\
\text { Elbow F/E } \\
\text { Wrist F/E }\end{array}$ & EMG & Passive assist & No \\
\hline ExoRob [60,61] & exo,R,e,U,G & 4 & $\begin{array}{l}\text { Elbow F/E } \\
\text { Forearm P/S, } \\
\text { Wrist F/E } \\
\text { Wrist R/U }\end{array}$ & PID, CTC, SMC & Passive assist & No \\
\hline ARMin-I [62] & exo,R,e,U,G & 4 & $\begin{array}{l}\text { Shoulder A/A, F/E, R } \\
\text { Elbow F/E }\end{array}$ & PD, CTC, IC & $\begin{array}{l}\text { Active assist } \\
\text { Passive assist }\end{array}$ & Yes (8) \\
\hline
\end{tabular}


Citation: Islam MR, Spiewak C, Rahman MH, Fareh R (2017) A Brief Review on Robotic Exoskeletons for Upper Extremity Rehabilitation to Find the Gap between Research Porotype and Commercial Type. Adv Robot Autom 6: 177. doi: 10.4172/2168-9695.1000177

Page 4 of 12

\begin{tabular}{|c|c|c|c|c|c|c|}
\hline ABLE [63] & exo,RP,e,U,G & 4 & $\begin{array}{l}\text { Shoulder A/A, F/E, R } \\
\text { Elbow F/E }\end{array}$ & $\mathrm{FF}$ & $\begin{array}{l}\text { Active assist } \\
\text { Passive assist }\end{array}$ & No \\
\hline BONES [64] & exo,R,p,U,G & 4 & $\begin{array}{l}\text { Shoulder A/A,F/E, R } \\
\text { Elbow F/E }\end{array}$ & $\mathrm{PC}, \mathrm{FC}$ & Active assist & No \\
\hline $\begin{array}{l}\text { Sutapun and Sangveraphunsiri } \\
\text { [65] }\end{array}$ & exo,R,p,U,G & 4 & $\begin{array}{l}\text { Shoulder A/A,F/E, R } \\
\text { Elbow F/E }\end{array}$ & IC & Active assist & No \\
\hline RUPERT [66] & exo,R,p,U,UG & 4 & $\begin{array}{l}\text { Shoulder F/E } \\
\text { Elbow F/E } \\
\text { Forearm P/S, } \\
\text { Wrist F/E }\end{array}$ & FFC & $\begin{array}{l}\text { Active assist } \\
\text { Passive assist }\end{array}$ & Yes (10) \\
\hline Dampace [67] & exo,R,h,U,G & 4 & $\begin{array}{l}\text { Shoulder A/A, F/E, R } \\
\text { Elbow F/E }\end{array}$ & PC, CTC & Passive assist & No \\
\hline Brackbill [68] & exo,RP,e,U,G & 4 & $\begin{array}{l}\text { Shoulder A/A, F/E, R } \\
\text { Elbow F/E }\end{array}$ & PD, CTC & $\begin{array}{l}\text { Active assist } \\
\text { Passive assist }\end{array}$ & No \\
\hline ALEx $[69,70]$ & exo,R,e,U,G & 4 & $\begin{array}{l}\text { Shoulder A/A, F/E, R } \\
\text { Elbow F/E }\end{array}$ & EMG & $\begin{array}{l}\text { Active assist } \\
\text { Passive assist }\end{array}$ & Yes (1) \\
\hline LIMPACT [71] & exo,R h,U,G & 4 & $\begin{array}{l}\text { Shoulder A/A, F/E, I/R } \\
\text { Elbow F/E }\end{array}$ & $\begin{array}{l}\text { CTC } \\
\text { IC }\end{array}$ & Passive assist & No \\
\hline Zhou [72] & exo,R h,U,G & 4 & $\begin{array}{l}\text { Shoulder A/A, F/E, I/R } \\
\text { Elbow F/E }\end{array}$ & EMG & Passive assist & No \\
\hline NEMS $[73,74]$ & exo,R e,U,G & 4 & $\begin{array}{l}\text { Shoulder A/A, F/E, I/R } \\
\text { Elbow F/E }\end{array}$ & PID & Passive assist & No \\
\hline Li [75] & exo,R e,U,G & 4 & $\begin{array}{l}\text { Shoulder A/A, F/E } \\
\text { Elbow F/E } \\
\text { Forearm P/S }\end{array}$ & EMG & Passive assist & No \\
\hline Pina-Martinez [32] & exo,R e,U,G & 4 & $\begin{array}{l}\text { Shoulder A/A, F/E, R } \\
\text { Elbow F/E }\end{array}$ & |---------- & Passive assist & No \\
\hline MAHI Exo II $[76,77]$ & exo,R,e,U,UG & 4 & $\begin{array}{l}\text { Elbow F/E } \\
\text { Forearm P/S } \\
\text { Wrist F/E } \\
\text { Wrist R/U } \\
\text { (NDA) }\end{array}$ & IC, AC & $\begin{array}{l}\text { Active assist } \\
\text { Passive assist }\end{array}$ & No \\
\hline L-EXOS [78] & exo,R,e,U,G & 5 & $\begin{array}{l}\text { Shoulder A/A, F/E, R } \\
\text { Elbow F/E } \\
\text { Forearm P/S }\end{array}$ & IC & $\begin{array}{l}\text { Active assist } \\
\text { Passive assist }\end{array}$ & Yes (6) \\
\hline MULOS [79] & exo,RP,e,U,UG & 5 & $\begin{array}{l}\text { Shoulder A/A, F/E, R } \\
\text { Elbow F/E } \\
\text { Forearm P/S }\end{array}$ & PID & $\begin{array}{l}\text { Active assist } \\
\text { Passive assist }\end{array}$ & No \\
\hline MARSE-5 [80] & exo,R,e,U,G & 5 & $\begin{array}{l}\text { Shoulder A/A, F/E, R } \\
\text { Elbow F/E } \\
\text { Forearm P/S }\end{array}$ & SMC & $\begin{array}{l}\text { Active assist } \\
\text { Passive assist }\end{array}$ & No \\
\hline MGA [26] & exo,R,e,U,G & 5 & $\begin{array}{l}\text { Shoulder A/A, F/E, R } \\
\text { Elbow F/E } \\
\text { Forearm P/S }\end{array}$ & IC, AC & $\begin{array}{l}\text { Active assist } \\
\text { Passive assist }\end{array}$ & No \\
\hline T-WREX [81] & exo,R,p,U,G & 5 & $\begin{array}{l}\text { Shoulder A/A, F/E, R } \\
\text { Elbow F/E } \\
\text { Finger Grasp }\end{array}$ & ------------- & $\begin{array}{l}\text { Active assist } \\
\text { Passive assist }\end{array}$ & Yes (51) \\
\hline RUPERT IV $[82,83]$ & exo,R,p,U,UG & 5 & $\begin{array}{l}\text { Shoulder A/A, F /E, R } \\
\text { Elbow F/E } \\
\text { Forearm P/S } \\
\text { Wrist F/E }\end{array}$ & FFC & $\begin{array}{l}\text { Active assist } \\
\text { Passive assist }\end{array}$ & Yes (6) \\
\hline MAHI [84] & exo,R,e,U,UG & 5 & $\begin{array}{l}\text { Elbow F/E } \\
\text { Forearm P/S } \\
\text { Wrist F/E } \\
\text { Wrist R/U } \\
\text { (NDA) }\end{array}$ & IC, AC & $\begin{array}{l}\text { Active assist } \\
\text { Passive assist }\end{array}$ & No \\
\hline John [85] & exo,R,e,U,UG & 5 & $\begin{array}{l}\text { Shoulder A/A, F/E, R } \\
\text { Elbow F/E } \\
\text { Forearm P/S }\end{array}$ & ------------- & Passive assist & No \\
\hline Mushage [86] & exo,R,U,UG & 5 & $\begin{array}{l}\text { Shoulder A/A, F/E, R } \\
\text { Elbow F/E } \\
\text { Wrist F/E }\end{array}$ & SMC & $\begin{array}{l}\text { Active assist } \\
\text { Passive assist }\end{array}$ & No \\
\hline Kang and Wang [87] & exo,R,e,UB,UG & 5 & $\begin{array}{l}\text { Shoulder A/A, R } \\
\text { Elbow F/E } \\
\text { Forearm P/S } \\
\text { Wrist F/E }\end{array}$ & RRC & Passive assist & No \\
\hline ARAMIS [88] & exo,R,e,B,G & 6 & $\begin{array}{l}\text { Shoulder A/A, F/E, R } \\
\text { Elbow F/E } \\
\text { Forearm P/S } \\
\text { wrist F/E }\end{array}$ & ----------- & $\begin{array}{l}\text { Active assist } \\
\text { Passive assist }\end{array}$ & Yes (14) \\
\hline
\end{tabular}


Citation: Islam MR, Spiewak C, Rahman MH, Fareh R (2017) A Brief Review on Robotic Exoskeletons for Upper Extremity Rehabilitation to Find the Gap between Research Porotype and Commercial Type. Adv Robot Autom 6: 177. doi: 10.4172/2168-9695.1000177

Page 5 of 12

\begin{tabular}{|c|c|c|c|c|c|c|}
\hline MIME [10,89] & eef,R,e,UB,G & 6 & $\begin{array}{l}\text { Shoulder } \\
\text { Elbow } \\
\text { (NDA) }\end{array}$ & |------------- & $\begin{array}{l}\text { Active assist } \\
\text { Passive assist } \\
\text { resist }\end{array}$ & Yes (57) \\
\hline Gentle/S $[28,90]$ & eef,R,e,U,G & 6 & $\begin{array}{l}\text { Shoulder } \\
\text { Elbow } \\
\text { Forearm } \\
\text { (NDA) }\end{array}$ & ----------- & $\begin{array}{l}\text { Active assist } \\
\text { Passive assist } \\
\text { resist }\end{array}$ & Yes (31) \\
\hline ARMin-III [91-94] & exo,R,e,U,G & 6 & $\begin{array}{l}\text { Shoulder A/A, F/E, R } \\
\text { Elbow F/E } \\
\text { Forearm P/S, } \\
\text { wrist F/E }\end{array}$ & PD, CTC, IC & $\begin{array}{l}\text { Active assist } \\
\text { Passive assist }\end{array}$ & No \\
\hline Chen [95] & exo,R e,U,G & 6 & $\begin{array}{l}\text { Shoulder A/A, F/E } \\
\text { Elbow F/E } \\
\text { Forearm P/S, } \\
\text { Wrist F/E } \\
\text { Wrist R/U }\end{array}$ & |---------- & Passive assist & No \\
\hline CABexo [96] & exo,R e,U,G & 6 & $\begin{array}{l}\text { Shoulder A/A, F/E } \\
\text { Elbow F/E } \\
\text { Forearm P/S, } \\
\text { Wrist F/E } \\
\text { Wrist R/U }\end{array}$ & |--------- & Passive assist & No \\
\hline 6-REXOS [97] & exo,R e,U,G & 4 & $\begin{array}{l}\text { Elbow F/E } \\
\text { Forearm P/S, } \\
\text { Wrist F/E } \\
\text { Wrist R/U }\end{array}$ & |--------- & Passive assist & No \\
\hline MAAT [98-100] & eef,R,e,UB,G & 7 & $\begin{array}{l}\text { Shoulder } \\
\text { Elbow } \\
\text { Forearm } \\
\text { (NDA) }\end{array}$ & |--------- & $\begin{array}{l}\text { Active assist } \\
\text { Passive assist }\end{array}$ & No \\
\hline CADEN-7 [101] & exo,RP,e,B,G & 7 & $\begin{array}{l}\text { Shoulder A/A, F/E, R } \\
\text { Elbow F/E } \\
\text { Forearm P/S, } \\
\text { Wrist F/E } \\
\text { Wrist R/U }\end{array}$ & PID, EMG & $\begin{array}{l}\text { Active assist } \\
\text { Passive assist }\end{array}$ & No \\
\hline MARSE-7 [60,102] & exo,R,e,U,G & 7 & $\begin{array}{l}\text { Shoulder A/A, F/E, R } \\
\text { Elbow F/E } \\
\text { Forearm P/S, } \\
\text { Wrist F/E } \\
\text { Wrist R/U }\end{array}$ & $\begin{array}{l}\text { PID, CTC, EMG, } \\
\text { SMC, SME }\end{array}$ & $\begin{array}{l}\text { Active assist } \\
\text { Passive assist }\end{array}$ & No \\
\hline SRE [103] & exo,R,p,U,G & 7 & $\begin{array}{l}\text { Shoulder A/A, F/E, R } \\
\text { Elbow F/E } \\
\text { Forearm P/S, } \\
\text { Wrist F/E } \\
\text { Wrist R/U }\end{array}$ & PID, IC & $\begin{array}{l}\text { Active assist } \\
\text { Passive assist }\end{array}$ & No \\
\hline SUEFUL-7 [29] & exo,PA,e,U,G & 7 & $\begin{array}{l}\text { Shoulder A/A, F/E, R } \\
\text { Elbow F/E } \\
\text { Forearm P/S, } \\
\text { Wrist F/E } \\
\text { Wrist R/U }\end{array}$ & EMG, FC & $\begin{array}{l}\text { Active assist } \\
\text { Passive assist }\end{array}$ & No \\
\hline Umemura [104] & eef,R,h,U,G & 7 & $\begin{array}{l}\text { Shoulder A/A, F/E, R } \\
\text { Elbow F/E } \\
\text { Forearm P/S, } \\
\text { Wrist F/E } \\
\text { Wrist R/U }\end{array}$ & |-------------- & Active assist & No \\
\hline Garrido [105] & exo,R,e,U,G & 7 & $\begin{array}{l}\text { Shoulder A/A, F/E, R } \\
\text { Elbow F/E } \\
\text { Forearm P/S, } \\
\text { Wrist F/E } \\
\text { Wrist R/U }\end{array}$ & $A C$ & $\begin{array}{l}\text { Active assist } \\
\text { Passive assist }\end{array}$ & No \\
\hline Rehab-Arm [106] & eef,R,h,U,G & 7 & $\begin{array}{l}\text { Shoulder A/A, F/E, R } \\
\text { Elbow F/E } \\
\text { Forearm P/S, } \\
\text { Wrist F/E } \\
\text { Wrist R/U }\end{array}$ & PID & Active assist & No \\
\hline CAREX-7 [107] & exo,R e,U,G & 7 & $\begin{array}{l}\text { Shoulder A/A, F/E, I/R } \\
\text { Elbow F/E } \\
\text { Forearm P/S, } \\
\text { Wrist F/E } \\
\text { Wrist R/U }\end{array}$ & CTC, PID & $\begin{array}{l}\text { Passive assist, } \\
\text { Active assist }\end{array}$ & No \\
\hline Kim and Kim [108] & exo,PA e,U,G & 7 & $\begin{array}{l}\text { Shoulder A/A, F/E, I/R } \\
\text { Elbow F/E } \\
\text { Forearm P/S, } \\
\text { Wrist F/E } \\
\text { Wrist R/U }\end{array}$ & ----------- & $\begin{array}{l}\text { Passive assist, } \\
\text { Active assist }\end{array}$ & No \\
\hline
\end{tabular}


Citation: Islam MR, Spiewak C, Rahman MH, Fareh R (2017) A Brief Review on Robotic Exoskeletons for Upper Extremity Rehabilitation to Find the Gap between Research Porotype and Commercial Type. Adv Robot Autom 6: 177. doi: 10.4172/2168-9695.1000177

Page 6 of 12

\begin{tabular}{|c|c|c|c|c|c|c|}
\hline NTUH-ARM [109] & exo,R,e,U,G & 9 & $\begin{array}{l}\text { Shoulder } \\
\text { Elbow } \\
\text { Forearm wrist } \\
\text { (NDA) }\end{array}$ & PID, IC, EMG & $\begin{array}{l}\text { Active assist } \\
\text { Passive assist }\end{array}$ & No \\
\hline IntelliArm [110] & exo,R,e,U,G & 10 & $\begin{array}{l}\text { Shoulder } \\
\text { Elbow } \\
\text { Forearm } \\
\text { Wrist } \\
\text { (NDA) }\end{array}$ & VRC & Active assist & No \\
\hline REHAROB [111] & eef,R,e,U,G & 12 & $\begin{array}{l}\text { Shoulder } \\
\text { Elbow } \\
\text { (NDA) }\end{array}$ & -------- & Active assist & Yes (8) \\
\hline Hand motion assist robot [112] & exo,R,e,U,G & 18 & $\begin{array}{l}\text { Wrist } \\
\text { Finger } \\
\text { (NDA) }\end{array}$ & PD & $\begin{array}{l}\text { Active assist } \\
\text { Passive assist }\end{array}$ & No \\
\hline
\end{tabular}

\section{Abbreviations}

Clinical test: The number inside bracket in the last column shows the number of patients.

Type: eef: End-effector type robot, exo: Exoskeleton type robot, e: Electric actuation, p: Pneumatic actuation, h: Hydraulic actuation, U: Unilateral, B: Bilateral, UB: Unilateral and Bilateral, R: Rehabilitation, PA: Power assistance, RP: Rehabilitation and Power assistance, G: Grounded-Exoskeleton's base is fixed to a location, UG: Ungrounded - base is movable.

\section{Movements}

A/A: Abduction/Adduction, F/E: Flexion/Extension, R: Internal/External rotation, P/S: Pronation/Supination, R/U: Radial/Ulnar deviation NDA: Not defined by basic anatomical movement.

\section{Control}

FC: Force control, FF: Force Feedback control, FFC: Force Forward control, PC: Position control, PD: Proportional Derivative control, PID: Proportional Integral Derivative control, CTC: Computed Torque control, IC: Impedance control, AC: Admittance control, EMG: Electromyography (EMG) based control, SMC: Sliding mode control, SME: Sliding mode control with exponential reaching law, PCM: Pulse code modulation scheme, VRC: Virtual reality based control, RC: Robust Control.

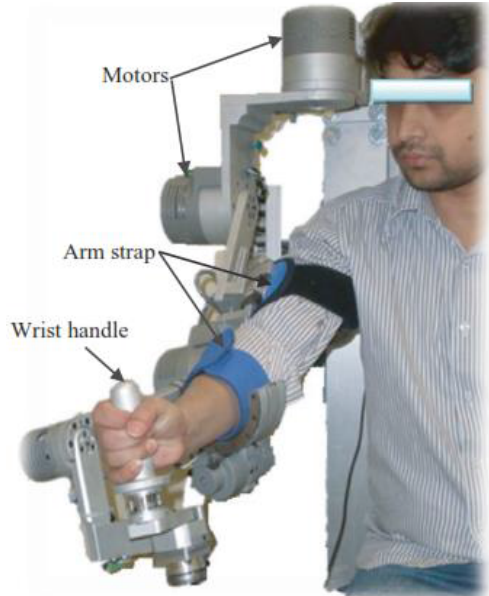

Figure 2: Exoskeleton type device (MARSE-7 [25])

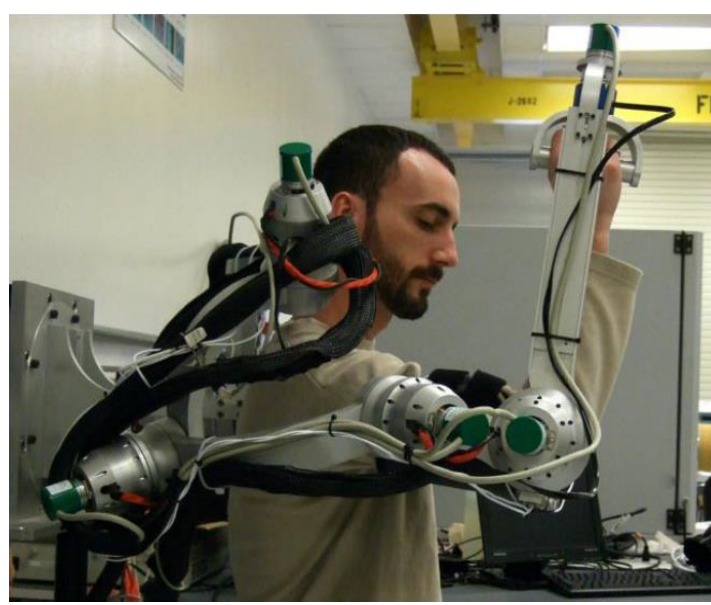

Figure 3: Rehabilitation type device (MGA exoskeleton [26]).

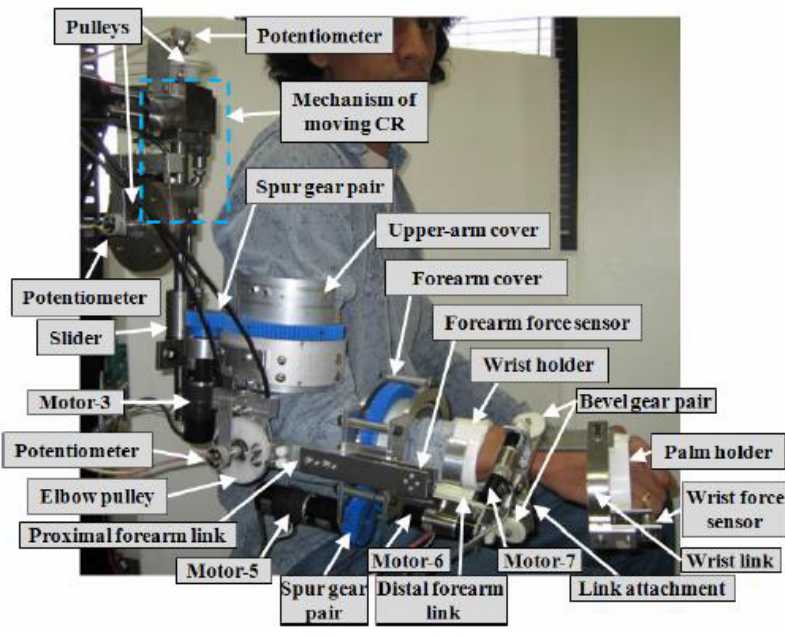

Figure 4: Power assistance device (SUEFUL-7 [27]).

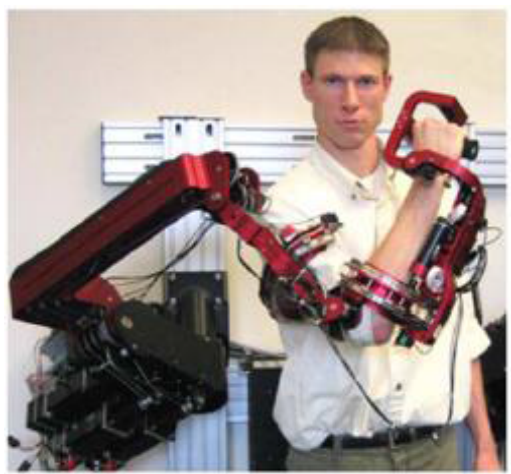

Figure 5: Both rehabilitation and power assistance type devices (CADEN-7 [28]). 
on the amount of misalignment [116]. In addition, misalignments between human and robot joint axes can also occur as a result of ignoring the motion of ICR in the exoskeleton robot [118]. There have been developed a plenty of exoskeletons that used a simple ball and socket joint in producing shoulder movement $[56,87,101,102,106]$. Reproducing shoulder movement by a ball and socket joint is not enough to define it since there are two more movements (motions of the glenohumeral joint - elevation and rotation). These movements are involved with all other movements of the arm and varying from person to person. Though their effect is slight, it should be taken into consideration while designing rehabilitation exoskeleton. Researchers used different techniques to minimize the effect of misalignment. In MEDARM, a cable driven system is proposed to deal with the effect of shoulder ICR movement [118]. Without using any additional mechanism, some research groups solved joint alignment and shoulder translation complexities by keeping trunk moveable $[78,101]$. The aforementioned approaches were applied to make shoulder and elbow aligned with the mechatronic structure of exoskeleton as closely as possible. Stienen et al. [116] suggested decoupling of joint and rotations and translations which would make the exoskeletons selfaligned. The major disadvantage of this solution is complexity and the reduction in interaction stiffness. Other researchers incorporated additional mechanism to make their devices aligned with the human upper limb's joint axes, leading to produce natural redundancy and shoulder complexities in addition to ball and socket joint $[26,62,81,91$ 93]. These projects were to find the motion of the glenohumeral joint $(\mathrm{GH})$ as a function of elevation of humerus head only by rotating glenohumeral joint about the acromioclavicular joint. Carignan et al. [26] have developed an empirical equation to find vertical displacement of GH joint. Whereas, Nef et al. [92] proposed an ergonomic shoulder model that optimized the movement of humerus head for a certain body weighted patients and mentioned the range for it as well. In order to find the other weight group patients, a linear scaling factor was introduced in later one. Both the works have included an unactuated joint to move humerus head. This solution is better than previous two approaches in producing trunk movement, close to natural. But it created complexity in structure and increased the inertia. In NEMS, eight additional passive degrees of freedom with four active series elastic actuators were used for the alignment of the motor axes to the human joint axes, regardless the user's specific anthropometry sizes [73]. Such a compliant architecture makes the device safer, reliable and, comfortable. Christensen and Bai [119] proposed a novel shoulder mechanism where a double parallelogram linkage is used to overcome the effect of shoulder ICR motion [50] used a instantaneous centre of rotation mechanism with two passive DOF to produce complex shoulder movement. In recent past, Li et al. [75] proposed a number of synthesis methods of self adapting upper-limb rehabilitation exoskeletons.

\section{Singularity}

The mechanical singularity is another issue that appears in exoskeleton when two axes of exoskeleton's joints (particularly axis for shoulder internal/external rotation and axis for forearm pronation/ supination) are aligned with each other, one DOF is lost and requires infinite torque to move exoskeleton away from this position. Malosio et al. [120] introduced elbow joint misalignment to get rid of singularity, limited to mimic the kinematics of upper extremity. The human upper limb has natural singularity and it does not create a trouble to move limb from singular position. Unlike human upper limb, actuators in exoskeleton requires infinite torque to move itself from singular position. Some researchers didn't consider the issue because it is rare to encounter a singular position in rehabilitation protocol $[21,101]$. But exoskeleton should be got rid of singularity because it can be stuck if somehow it's been in singular position. There are two areas where effort can be given to solve the issue. Researchers might address the issue in design of exoskeleton's structure or they can include it in control strategy, to make exoskeleton safe in operation and reliable.

\section{Actuation mechanism}

Actuators provide the necessary torques to run the exoskeletons. The actuator is one of those stuffs that is responsible to increase the weight of exoskeletons. Therefore, researchers are looking for actuators that have high power to weight ratio. There are three main types of actuators i.e., electrical, pneumatic and hydraulic actuators that have been used in past exoskeletons. The typical examples of exoskeletons where pneumatic actuators were used are $[64,82,103]$. The efficiency of pneumatic actuation depends on pressure loss due to friction, air's compressibility and purity of air. It has high power to weight ratio over electric motors. The major disadvantage is that the bandwidth which it is operating on is relatively low $(5 \mathrm{~Hz})$ which limit the rate at which they can respond to command signals [121]. Some research groups have used hydraulics actuation in their work $[35,67]$ which has high power to weight ratio. But hydraulic actuator produces less efficient motion if fluid leaks, pressure loss happens. Also it requires equipment to reduce noise, what makes system more complex. To actuate the upper limb exoskeletons, electrical motors have been used in most devices $[27,76,77,93,97,101,102]$ since electrical motors can produce large amount of torque and highly precise motion despite they are heavy compared to other two. The actuators to be used in exoskeleton should (a) be light (b) have high operating bandwidth (c) capable of producing precise motion and (d) deliver large amount of torque.

\section{Power transmission}

In order to turn research prototype of upper limb exoskeleton into commercial version, power transmission should be more novel and sophisticated which would help it make simple, low inertia and to provide required power. Incessant variable power transmission is required in exoskeleton during operation. The transmission can be done by cable drive, wire rope drive, gear train transmission, pulley drive, harmonic drive etc. Some approach used cable driven actuation to run their exoskeleton $[96,103,107$,$] . One of the flexibility for cable$ drive is that it can be fitted at spots within exoskeleton where it would be hard to place other types. This kind also provides benefits in terms of low inertia and simplicity, ensures fast response times, and long range transmission of force and power but cable can easily stretch and slip which leads to produce different joint movement than the desired $[107,122]$ proposed a cable tension programming where quadratic programming is applied to optimize the cable tensions.

In contrast, transmission that uses gear trains inherently contains some clearance between meshed teeth what causes friction and backlash [123]. Moreover, it requires lubrication, significant space for gear box and regular maintenance which discouraged researchers to use it in upper limb exoskeletons. However, some research group used harmonic drives to avoid backlash $[25,92]$. This transmission offers compactness, light weight, high gear ratios and high torque capability that makes it popular among research community of upper limb exoskeleton for rehabilitation [124]. Apart from overall transmission, there are some joints like the rotation about axes which are along the length of upper limb (i.e., shoulder internal/external rotation and forearm pronation/ supination) are somewhat complex in regards to power transmission because placement of actuator and shaft along the axis of rotation is 
practically infeasible due to the anatomical configuration of the human arm. Rahman et al. [25] have developed an innovative gear mechanism where motion is transmitted from an anti-backlash gear (mounted on a motor shaft) to an open-type, custom-made meshing ring gear attached rigidly to the upper arm cup. But still there is need to come up with more novel approach in terms of lightness, compactness, functionality and fast response.

\section{Decoupling}

The interactive torques between joints hamper the exoskeleton to follow desired trajectory which is monumental for rehabilitation. For instance, if the exoskeleton is not perfectly decoupled, torque of a joint contributes to neighboring joints, leads to improper estimation of torques. Decoupling would definitely help produce smooth motion and torque as much needed $[120,122]$. In Auxilio, decoupled mechanism using tendon drive is used to decouple the individual joint movement [125]. But tendon can easily stretch and slip, leading to cause disrupt the power transmission which is why other research groups are not interested to this solution [122]. In addition, it makes the hardware no longer simple. However, the most of the exoskeletons (Dampace, ASSIST, AMBLE, BONES, MARSE etc.) that are currently available are not decoupled. This effect has been considered and compensated in exoskeleton's controller. This solution produces more appeal than the previous approach to the researchers since it does no change in hardware.

\section{Backdriveability}

The backdriveability is another important issue that needs to be addressed since the patients are supposed to have control sharing of movement when they are given active therapy. With the passage of time, patients regain their lost motor function, therefore exoskeleton must allow patients when they are able to move their limb on own effort. The CADEN-7, a 4 DOF exoskeleton and ABLE exoskeleton are backdriveable $[63,65,101]$.

\section{Control Issues}

The dynamics of upper limb exoskeleton is non-linear in nature as it comprises of many links, joint, actuators and sensor. The centrifugal and Coriolis forces, and friction at joints causes non-linearity to appear in exoskeleton's manipulator dynamics. Therefore, unlike control approach used in industrial robotics, controlling of upper arm exoskeleton necessities non-linear control strategy [102]. In rehabilitation, robotic devices have been deployed to assist patients after stroke to move their impaired limb through a pre-defined trajectory. This movement uses both a linear and nonlinear approach $[41,68,91]$ used a PD controller which has limitations of having some steady date error in trajectory tracking. On the other hand $[58,60,73,74,106,107,126]$ used a different approach (PID) in which an integral term was added in the controller to compensates for steady state error during the robot-aided therapy. But the shortcomings of PID controller are that the joints are treated as independent and it is purely error driven which might generate a large amount of torque if exoskeleton is stuck in somewhere because of accumulation of error.

Basically, it is expected that controller used in exoskeleton should be as much as robust so that they could be compatible with the external disturbances produced by the environment where robot works. That is why research groups have been interested in using nonlinear control technique i.e., computed torque control (CTC), impedance control, admittance control, neuro-fuzzy control, sliding mode control
(SMC), sliding mode control with exponential reaching law (sMERL), electromyographic (EMG) control, adaptive control etc. to pay for these issues.

Some research groups used CTC method to control the motion of their exoskeletons $[67,71,107]$. This approach is based on manipulator dynamics and able to handle disturbances. But it is difficult to model accurate dynamics of the manipulator since mass/inertia, damping, centrifugal and Coriolis term varies from patient to patient. In addition, generally friction is being neglected to avoid complexity in modelling. Thus, the tracking performance appreciably be reduced for CTC.

In impedance control force was being controlled in which position is given to the closed loop controller as feedback [26,109]. In those attempts, the Jacobian has been used to obtain required torques to follow the desired trajectory. But the limitation of impedance control is that system becomes unstable if the mechanical impedance is high and it requires natural dynamics as well [127]. On the contrary, admittance controller, used in many haptic devices, position was being controlled while force taken as feedback $[32,84]$. The main advantage of using admittance controller is that it does not require model feedforward to compensate for the natural dynamics rather it depends on the high PD gains of the joint position servo-loop to reject unmodeled dynamics [26]. However, this type of controller holds its stability until it has high impedance.

In order to control parameters (i.e., mass, length of the limb, muscle force etc.) which may vary from subject to subject, proposed sliding mode fuzzy adaption control technique for upper limb exoskeleton $[124,128]$ used a back-propagation neural network based on EMG to follow a desired trajectory whereas $[50,129]$ used a neurofuzzy adaption controller based on EMG signals. But neural network and fuzzy logic control require heavy computation. Moreover coaching staff i.e., Microsoft Kinect is used in some non-actuated exoskeleton where patients movement is going to be monitored and it provides feedback but does not participate in control directly [81].

However, one of the challenge for upper limb exoskeleton is control sharing (active therapy mode) when patients start regaining their lost motor function with the passage of time, at this stage exoskeleton must allow patients to move their limb on own attempt. This is what researchers called as much as needed control. Though in the field of upper extremity robotic devices, researchers have implemented different control scheme in order to obtain a fine control and tracking, still there are room to develop the controller more intelligent. For example, a therapist can notice whether patients are feeling any pain during rehabilitation, therefore, he/she could adjust with the situation to provide a safe therapy. In addition, the patient's muscle contraction varies with the body temperature which needs to be taken into account in control approach [130]. Also, level of disability for every patient is not equal, but same robotic device would be using for all. Moreover, most of the current exoskeletons follows desired trajectory but do not consider the force which also demands more attention. These are the issues which will make exoskeleton safe, efficient and increase its use in rehabilitation program that researchers need to consider when designing control algorithm.

\section{Discussion}

A few of the robotic devices have been tested in the clinical environment. The rests are not being able to show efficacy in rehabilitation program. The reason behind this is that exoskeletons for rehabilitation are not welcome yet in clinical setting. However, the 
Citation: Islam MR, Spiewak C, Rahman MH, Fareh R (2017) A Brief Review on Robotic Exoskeletons for Upper Extremity Rehabilitation to Find the Gap between Research Porotype and Commercial Type. Adv Robot Autom 6: 177. doi: 10.4172/2168-9695.1000177

Page 9 of 12

rapid advancement in technology has accelerated the development of the upper limb exoskeleton. The researchers have been working on control method including linear, nonlinear and hybrid, control input (EMG, EEG signals, Brain signals), actuation, power transmission, sensor technologies etc. to make reliable assistive robotic devices for rehabilitation program. There are room to develop actuation, power transmission, portability, functionality, compactness and weight. Also modularity is something, offers advantages over traditional robotics in terms of reconfigurability that allows upper limb exoskeleton being used only for shoulder, elbow or wrist depending on patient's requirement, researchers working on upper limb exoskeleton wish to have in their system [131]. The exoskeleton needs high power to weight ratio with high bandwidth, simpler mechanism for transmission with minimum loss. The decoupling should be done such a way so that it would help to obtain finer coordination of joint torques but not to make the exoskeleton complex and weird posture. In addition, backdriveable exoskeleton helps to provide as much as needed torque so that patients might be taking part in motion achievement during therapy [132].

For controller design, control sharing is the most important thing which should be more novel. Doing so requires estimation of muscle force and sending it as a feedback to the controller. The factors that affect estimation of muscle force should be taken into consideration while designing control algorithm. Safety is the top priority issue, any time exoskeleton should be stopped if something goes wrong. The controller should be acting like a therapist and can adjust the operation if patients feel pain [133].

As we discussed earlier researchers have been developing many exoskeletons over last two decades, still use of exoskeleton is not common in rehabilitation and commercialized. In this paper, it is being tried to figure out the reasons why a few of devices have commercial version however there is a lot of exoskeletons are currently available. The review came up with the following design considerations for upper limb exoskeleton: low mass, excellent power/weight ratio, accurate and automatic compensation for gravity, compactness, natural redundancy, greater range of motion, safe operation, reliability in all operations, relatively low complexity and low engineering and construction cost, simple fitting and removal, comfort in wearing, low/no maintenance, portability, modularity, home use and affordable cost $[80,103]$.

\section{Conclusion}

As mentioned earlier that the number of stroke patients is projected high and one to one rehabilitation program would be quite labor intensive and impossible due to shortage of therapist. Researchers have developed many exoskeletons for rehabilitation program which are technologically advanced. Their efficacy and reliability in therapy is still unproved because of not having much clinical evidence. This with cost constraint would limits commercialization of these exoskeletons which are already developed. Producing these exoskeletons commercially is essential. Otherwise it would not be possible to provide therapy many people. It is hoping that researchers will make new and effective solution to the reasons stated in this paper and this document would help the new researcher to direct themselves to identify reasons and thereby finding solution.

\section{Conflict of Interest}

The author(s) declare(s) that there is no conflict of interest regarding the publication of this paper.

\section{References}

1. Benjamin EJ, Blaha MJ, Chiuve SE, Cushman M, Das SR, et al. (2017) Heart
Disease and Stroke Statistics 2017 Update. A Report from the American Heart Association. Circulation 136: 230-235

2. Heidenreich P, Trogdon J Khavjou OA, Dracup K, Ezekowitz MD, et al. (2011) Forecasting the Future of Cardiovascular Disease. A Policy Statement from the American Heart Association. Circulation 123: 933-944.

3. Poli P, Morone G, Rosati G, Masiero S (2013) Robotic Technologies and Rehabilitation: New Tools for Stroke Patients' Therapy. BioMed Research International 2013: 153872

4. Reid DC (1992) Sports Injury Assessment and Rehabilitation. New York, NY: Churchill Livingstone.

5. Mehta JA, Bain GI (2004) Elbow dislocations in adults and children. Clin Sports Med 23: 609-627.

6. Dodson CC, Cordasco FA (2008) Anterior glenohumeral joint dislocations. Orthop Clin North Am 39: 507-518.

7. Mozaffarian D, Benjamin EJ, Go AS, Arnett DK (2015) Heart disease and stroke statistics-2015 update: a report from the American Heart Association: Circulation. American Heart Association 131: e29-e322.

8. Roger VL, Go AS, Lloyd-Jones DM (2011) Heart disease and stroke statistics-2011 update: a report from the American heart association. Circulation 123: e18-e20.

9. Teasell RW, Kalra L (2004) What's New in Stroke Rehabilitation. Stroke 35: 383-385.

10. Lum PS, Burgar CG, Shor PC, Majmundar M, Van der Loo M (2002) Robotassisted movement training compared with conventional therapy techniques fo the rehabilitation of upper-limb motor function after stroke. Archives of Physical Medical and Rehabilitation 83: 952-959.

11. Dobkin BH (2004) Strategies for stroke rehabilitation. Lancet Neurol 3: 528-536

12. Bayona NA, Bitensky J, Salter K, Teasell R (2005) The role of task specific training in rehabilitation therapies. Top Stroke Rehabil 12: 58-65.

13. Masiero S, Celia A, Armani M, Rosati G (2006) A novel robot device in rehabilitation of post-stroke hemiplegic upper limbs. Aging Clinical and Experimental Research 18: 531-535.

14. Prange GB, Jannink MJ, Groothuis-Oudshoorn CG (2006) Systematic review of the effect of robot-aided therapy on recovery of the hemiparetic arm after stroke. J Rehabil Res Dev 43: 171-184.

15. Kwakkel G, Kollen BJ, Krebs HI (2007) Effects of robot-assisted therapy on upper limb recovery after stroke: a systematic review. Neurorehab Neura Repair 22: 111-121.

16. Masiero S, Celia A, Rosati G, Armani M (2007) Robotic assisted rehabilitation of the upper limb after acute stroke. Archives of Physical Medicine and Rehabilitation 88: 142-149.

17. Taub E, Uswatte G, Pidikiti R (1999) Constraint-induced movement therapy: a new family of techniques with broad application to physical rehabilitation clinical review. J Rehabil Res Dev 36: 237-251.

18. Dromerick AW, Edwards DF, Hahn M (2000) Does the application of constraintinduced movement therapy during acute rehabilitation reduce arm impairment after ischemic stroke? Stroke 31: 2984-2988.

19. Fazekas G, Horvath M, Troznai T, Toth A (2007) Robot-mediated upper limb physiotherapy for patients with spastic hemiparesis: a preliminary study. $J$ Rehab Med 39: 580-582

20. Miltner $\mathrm{WH}$, Bauder $\mathrm{H}$, Sommer $\mathrm{M}$ (1999) Effects of constraint-induced movement therapy on patients with chronic motor deficits after stroke a replication. Stroke 30: 586-592.

21. Kommu SS (2007) Rehabilitation Robotics. Vienna, Austria: Itech Education and Publishing.

22. Jarrassé N, Proietti T, Crocher V, Robertson J, Sahbani A, et al. (2014) Robotic Exoskeletons: A perspective for the rehabilitation of arm coordination in stroke patients. Frontiers in Human Neuroscience 8: 947.

23. Maciejasz P, Eschweiler J, Hahn KG, Troy AJ, Leonhardt S (2014) A survey on robotic devices for upper limb rehabilitation. Journal of Neuroengineering and Rehabilitation 11: 1.

24. Krebs HI, Volpe BT, Williams D, Celestino J, Charles SK, et al. (2007) Robotaided neurorehabilitation: a robot for wrist rehabilitation. IEEE Trans Neura 
Citation: Islam MR, Spiewak C, Rahman MH, Fareh R (2017) A Brief Review on Robotic Exoskeletons for Upper Extremity Rehabilitation to Find the Gap between Research Porotype and Commercial Type. Adv Robot Autom 6: 177. doi: 10.4172/2168-9695.1000177

Syst Rehabil Eng 15: 327-335.

25. Rahman MH, Rahman MJ, Cristobal OL, Saad M, Kenné JP, et al. (2015) Development of a whole arm wearable robotic exoskeleton for rehabilitation and to assist upper limb movements. Robotica CJO 33: 19-39.

26. Carignan C, Tang J, Roderick S, Naylor M (2007) A Configuration-Space Approach to Controlling a Rehabilitation Arm Exoskeleton. Rehabil Robot, pp: 689-695.

27. Gopura RARC, Kiguchi K, Li Y (2009) SUEFUL-7: A 7DOF upper-limb exoskeleton robot with muscle-model-oriented EMG-based control. IEEE/RS J International Conference on Intelligent Robots and Systems (IROS), pp: 11261131.

28. Amirabdollahian F, Loureiro R, Gradwell E, Collin C, Harwin W, et al. (2007) Multivariate analysis of the Fugl-Meyer outcome measures assessing the effectiveness of GENTLE/S robot-mediated stroke therapy. J Neuroeng Rehabil 4: 4.

29. BabaiasI M, Mahdioun SH, Jaryani P, Yazdani M (2015) A review of technological and clinical aspects of robot-aided rehabilitation of upper-extremity after stroke. Disability Rehabil: Assistive Technol 11: 263-280.

30. Hesse S, Konrad M, Bardeleben A, Werner C (2003) Robot-assisted arm trainer for the passive and active practice of bilateral forearm and wrist movements in hemiparetic subjects. Arch Phys Med Rehabil 84: 915-920.

31. Kung PC, Ju MS, Lin CCK (2007) Design of a forearm rehabilitation robot IEEE 10th International Conference on Rehabilitation Robotics ICORR), pp: 228-233

32. Colombo R, Pisano F, Mazzone A, Delconte C, Micera S, et al. (2007) Design strategies to improve patient motivation during robot-aided rehabilitation. J Neuroeng Rehabil 4: 3.

33. Song R, Tong KY, Hu XL, Zheng XJ (2007) Myoelectrically Controlled Robotic System That Provide Voluntary Mechanical Help for Persons after Stroke. IEEE 10th International Conference on Rehabilitation Robotics (ICORR)), pp: 246249.

34. Hu XL, Tong KY, Song R, Zheng X.J, Lui KH, et al. (2009) Quantitative evaluation of motor functional recovery process in chronic stroke patients during robot-assisted wrist training. J Electromyogr Kinesiol 19: 639-650.

35. Pylatiuk C, Kargov A, Gaiser I, Werner T, Schulz S, et al. (2009) Design of a flexible fluidic actuation system for a hybrid elbow orthosis. IEEE International Conference on Rehabilitation Robotics (ICORR)), pp: 167-171.

36. Kiguchi K, Esaki R, Tsuruta T, Watanabe K, Fukuda T (2003) An exoskeleton system for elbow joint motion rehabilitation. IEEE/ASME International Conference on Advanced Intelligent Mechatronics (AIM)), pp: 1228-1233.

37. Cheng HS, Ju MS, Lin CCK (2003) Improving elbow torque output of stroke patients with assistive torque controlled by EMG signals. J Biomech Eng 125 $881-886$

38. Sulzer JS, Peshkin MA, Patton JL (2007) Design of a mobile, inexpensive device for upper extremity rehabilitation at home. International Conference on Rehabilitation Robotics (ICORR)), pp: 933-937.

39. Beigzadeh B, llami M, Najafian S (2015) Design and development of one degree of freedom upper limb exoskeleton. 3rd RSI International Conference on Robotics and Mechatronics (ICROM)), pp: 223-228.

40. Hosseini M, Meattini R, Palli G, Melchiorri C (2017) A wearable robotic device based on twisted string actuation for rehabilitation and assistive applications. J Robot 2017: 11.

41. Jarrett C, McDaid A (2017) Robust control of a cable-driven soft exoskeleton joint for intrinsic human-robot interaction. IEEE Transactions on Neural Systems and Rehabilitation Engineering 99: 1-1.

42. Sasaki D, Noritsugu D, Takaiwa M (2004) Development of Active Support Splint Driven by Pneumatic Soft Actuator (ASSIST). Journal of Robotics and Mechatronics 16: 497-502.

43. Papadopoulos E, Patsianis G (2007) Design of an Exoskeleton Mechanism for the Shoulder Joint. Twelfth World Congr. In Mechanism and Machine Sci, pp: 1-6.

44. Freeman CT, Hughes AM, Burridge JH, Chappell PH, Lewin PL, et al. (2009) A robotic workstation for stroke rehabilitation of the upper extremity using FES. Med Eng Phys 31: 364-373.
45. Chang JJ, Tung WL, Wu WL, Huang MH, Su FC (2007) Effects of robot-aided bilateral force-induced isokinetic arm training combined with conventional rehabilitation on armmotor function in patients with chronic stroke. Arch Phys Med Rehabil 88: 1332-1338.

46. Rosen J, Brand N. Fuchs MB, Arcan M (2001) A Myosignal-Based Powered Exoskeleton System. IEEE Trans on Syst Man Cybern 31: 210-222.

47. Khan AM, Yun DW, Ali MA, Zuhaib KM, Yuan C, et al. (2016) Passivity based adaptive control for upper extremity assist exoskeleton. International Journal of Control, Automation and Systems 14: 291-300.

48. Triwiyanto, Wahyunggoro O, Nugroho HA, Herianto (2016) String actuated upper limb exoskeleton based on surface electromyography control. 6th International Annual Engineering Seminar (InAES)), pp: 176-181.

49. Reinkensmeyer DJ, Kahn LE, Averbuch M, McKenna-Cole A, Schmit BD, et al. (2000) Understanding and treating armmovement impairment after chronic brain injury: progress with the ARM guide. J Rehabil Res Dev 37: 653-662.

50. Kiguchi K, Rahman MH, Sasaki M, Teramoto K (2008) Development of a 3DOF mobile exoskeleton robot for human upper-limb motion assist. Robotics and Autonomous Systems 56: 678-691.

51. Rosati G, Gallina P, Masiero S (2007) Design, implementation and clinical tests of a wire-based robot for neurorehabilitation. IEEE Trans Neural Syst Rehabil Eng 15: 560-569.

52. Spencer SJ, Klein J, Minakata K, Le V, Bobrow JE, et al. (2008) A low cost parallel robot and trajectory optimization method for wrist and forearm rehabilitation using the Wii. 2nd IEEE RAS \& EMBS International Conference on Biomedical Robotics and Biomechatronics (BioRob)), pp: 869-874.

53. Takaiwa M, Noritsugu T (2005) Development of wrist rehabilitation equipmen using pneumatic parallel manipulator. IEEE International Conference on Robotics and Automation (ICRA)), pp: 2302-2307.

54. Rocon E, Belda-Lois JM, Ruiz AF, Manto M, Moreno JC, et al. (2007) Design and Validation of a Rehabilitation Robotic Exoskeleton for Tremor Assessment and Suppression. IEEE Transactions on Neural Systems and Rehabilitation Engineering 15: 367-378

55. Ruiz AF, Rocon E, Forner-Cordero A (2009) Exoskeleton-Based Robotic Platform Applied in Biomechanical Modelling of the Human Upper Limb. App Bionics Biomechanics 6: 2 .

56. Rosales Y, Lopez R, Rosales I, Salazar S, Lozano R (2015) Design and modeling of an upper limb exoskeleton. 19th International Conference on System Theory, Control and Computing (ICSTCC)), pp: 266-272.

57. Mahdavian M, Toudeshki AG, Yousefi-Koma A (2015) Design and Fabrication of a 3DoF Upper Limb Exoskeleton. RSI International Conference on Robotics and Mechatronics IEEE Explorer)

58. Sharma MK, Ordonez R (2016) Design and fabrication of an intention based upper-limb exo-skeleton. IEEE International Symposium on Intelligent Control (ISIC)), pp: 1-6.

59. Madani T, Daachi B, Djouani K (2017) Modular-Controller-Design-Based Fas Terminal Sliding Mode for Articulated Exoskeleton Systems. IEEE Transactions on Control Systems Technology 25: 1133-1140.

60. Rahman M, Ouimet TK, Saad M, Kenne JP, Archambault P (2010) Development and control of a wearable robot for rehabilitation of elbow and Shoulder joint movements. IECON 2010-36 $6^{\text {th }}$ Annual Conference on IEEE Industrial Electronics Society (IEEE)), pp: 1506-1511.

61. Rahman MH, Saad M, Kenne JP Archambault PS (2010) Modeling and Development of an Exoskeleton Robot for Rehabilitation of Wrist Movements. IEEE/ASME International Conference on Advanced Intelligent Mechatronics (AIM 2010).

62. Nef T, Mihelj M, Kiefer G (2007) ARMin-Exoskeleton for arm therapy in stroke patients. IEEE 10th International Conference on Rehabilitation Robotics), pp: 68-74

63. Garrec P, Friconneau JP, Measson Y, Perrot $Y$ (2008). ABLE, an innovative transparent exoskeleton for the upper-limb. IEEE/RSJ International Conference on Intelligent Robots and Systems, pp: 1483-1488.

64. Klein J, Spencer S, Allington J, Bobrow JE, Reinkensmeyer DJ (2010) Optimization of a parallel shoulder mechanism to achieve a high-force, lowmass, robotic-arm exoskeleton. Robotics, IEEE Trans 26: 710-715.

65. Sutapun A, Sangveraphunsiri V (2015) A 4-DOF Upper Limb Exoskeleton for 
Citation: Islam MR, Spiewak C, Rahman MH, Fareh R (2017) A Brief Review on Robotic Exoskeletons for Upper Extremity Rehabilitation to Find the Gap between Research Porotype and Commercial Type. Adv Robot Autom 6: 177. doi: 10.4172/2168-9695.1000177

Stroke Rehabilitation: Kinematics Mechanics and Control. IJMERR 4: 269-272.

66. Sugar TG, Jiping H, Koeneman EJ, Koeneman JB, Herman R, et al. (2007) Design and control of RUPERT: A device for robotic upper extremity repetitive therapy. IEEE Transactions on Neural Systems and Rehabilitation Engineering 15: $336-346$

67. Stienen A, Hekman E, Prange G, Jannink M, Aalsma A, et al. (2009) Design of an exoskeleton for force-coordination training in upper-extremity rehabilitation. J Med Devices 3: 031003.

68. Brackbill EA, Mao Y, Agrawal SK, Annapragada M, Dubey VN (2009) Dynamics and Control of a 4-dof Wearable Cable-Driven Upper Arm Exoskeleton. Kobe: IEEE, pp: 2300-2305

69. Pirondini E, Coscia M, Marcheschi S, Roas G, Salsedo F, et al. (2014) Evaluation of a New Exoskeleton for Upper Limb Post-stroke Neuro-rehabilitation: Preliminary Results. Replace, Repair, Restore, Relieve - Bridging Clinical and Engineering Solutions in Neurorehabilitation, pp: 637-645.

70. Stroppa F, Loconsole C, Marcheschi S, Frisoli A (2016) A Robot-Assisted Neuro-Rehabilitation System for Post-Stroke Patients' Motor Skill Evaluation with ALEx Exoskeleton. Converging Clinical and Engineering Research on Neurorehabilitation II. Springer International Publishing AG 2017, pp: 501-505.

71. Otten A, Voort C, Stienen A, Aarts R, Asseldonk, et al. (2015) LIMPACT: A Hydraulically Powered Self-Aligning Upper Limb Exoskeleton. IEEE/ASME Transactions on Mechatronics 20: 2285-2298.

72. Zhou L, Bai S, Andersen MS, Rasmussen J (2015) Modeling and design of a spring-loaded, cable-driven, wearable exoskeleton for the upper extremity. Modeling, Identification and Control 36: 167-177.

73. Crea S, Cempini M, Moise M, Baldoni A, Trigili E, et al. (2016) A nove shoulder-elbow exoskeleton with series elastic actuators. Biomedical Robotics and Biomechatronics (BioRob), pp: 1248-1253.

74. Accogli A, Grazi L, Crea S, Panarese A, Carpaneto J, et al. (2017) EMGBased Detection of User's Intentions for Human-Machine Shared Control of an Assistive Upper-Limb Exoskeleton, In: Wearable Robotics: Challenges and Trends: Proceedings of the $2^{\text {nd }}$ International Symposium on Wearable Robotics, Segovia, Spain, Gonzalez-Vargas J, Ibanez J, Contreras-Vidal JL, Kooij HVD, Pons JL editors. Cham: Springer International Publishing, pp: 181-185.

75. Li Z, Huang Z, He W, Su CY (2017) Adaptive impedance control for an upper limb robotic exoskeleton using biological signals. IEEE Transactions on Industrial Electronics 64: 1664-1674.

76. Fitle KD, Pehlivan AU, Malley MKO (2015) A robotic exoskeleton for rehabilitation and assessment of the upper limb following incomplete spinal cord injury. Robotics and Automation, pp: 4960-4966.

77. Bhagat NA, Venkatakrishnan A, Abibullaev B, Artz EJ, Yozbatiran N, et al (2016) Design and Optimization of an EEG-Based Brain Machine Interface (BMI) to an Upper-Limb Exoskeleton for Stroke Survivors. Frontiers in Neuroscience 10: 122

78. Frisoli A, Salsedo F, Bergamasco M, Rossi B, Carboncini CM (2009) A forcefeedback exoskeleton for upper-limb rehabilitation in virtual reality. Appl Bionics Biomech 6: 115-126.

79. Johnson GR, Carus DA, Parrini G, Marchese SS, Valeggi R (2001) The design of a five-degree-of-freedom powered orthosis for the upper limb. Proc Inst Mech Eng H 215: 275-284.

80. Rahman M, Ouimet TK, Saad M, Kenne JP, Archambault P (2012) Development and control of a robotic exoskeleton for shoulder, elbow and forearm movement assistance. Applied Bionics and Biomechanics 9: 275-292.

81. Sanchez R, Reinkensmeyer D, Shah P, Liu J, Rao S, et al. (2004) Monitoring functional arm movement for home-based therapy after stroke. Conf Proc IEEE EngMed Biol Soc 7: 4787-4790.

82. Balasubramanian S, Wei R, Perez M, Shepard B, Koeneman E, et al. (2008) An exoskeleton robot for assisting rehabilitation of arm functions. Virtual Rehabil, pp: 163-167

83. Balasubramanian S, He J (2012) Adaptive Control of a Wearable Exoskeleton for Upper-Extremity Neurorehabilitation. Appl Bionics and Biomech 9: 1.

84. Gupta A, O'Malley M (2006) Design of a haptic arm exoskeleton for training and rehabilitation. IEEE ASME Trans Mechatronics 11: 280

85. John MRS, Thomas N, Sivakumar VPR (2016) Design and Development of
Cable Driven Upper Limb Exoskeleton for Arm Rehabilitation. Internationa Journal of Scientific \& Engineering Research 7: 1432-1440.

86. Mushage BO, Chedjou JC, Kyamakya K (2017) Fuzzy neural network and observer-based fault-tolerant adaptive nonlinear control of uncertain 5-DOF upper-limb exoskeleton robot for passive rehabilitation. Nonlinear Dynamics 87: 2021-2037.

87. Kang HB, Wang JH (2015) Adaptive robust control of 5 DOF Upper-limb exoskeleton robot. Int J Control, Automation and Systems 13: 733-741.

88. Pignolo L, Dolce G, Basta G, Lucca LF, Serra S, et al. (2012) Upper limb rehabilitation after stroke: ARAMIS a "robo-mechatronic" innovative approach and prototype. 4th IEEE RAS \& EMBS Int. Conf. Biomedical Robotics and Biomechatronics (BioRob)), pp: 1410-1414.

89. Lum PS, Burga CG, van der Loos M, Shor PC, Majmundar M, et al. (2006) MIME robotic device for upper-limb neurorehabilitation in subacute stroke subjects: A follow-up study. J Rehabil Res Dev 43: 631-642.

90. Coote S, Murphy B, Harwin W, Stokes E (2008) The effect of the GENTLE/s robot-mediated therapy system on arm function after stroke. Clin Rehabil 22 395-405.

91. Nef T, Mihelj M, Riener R (2007) ARMin: a robot for patient-cooperative arm therapy. Medical \& Biological Engineering \& Computing 45: 887-900.

92. Nef T, Guidali M, Klamroth-Marganska V, Riener R (2009) Armin exoskeleton robot for stroke rehabilitation. World Congress on Medical Physics and Biomedical Engineering 25: 1-9.

93. Nef T, Guidali M, Riener R (2009) ARMin III-arm therapy exoskeleton with an ergonomic shoulder actuation. Applied Bionics and Biomechanics 6: 127-142.

94. Guidali M, Duschau-Wicke A, Broggi S (2011) A robotic system to train activities of daily living in a virtual environment. Med Biol Eng Comput 49: 1213-1223.

95. Chen Y, Fan J, Zhu Y, Zhao J, Cai H (2015) A passively safe cable driven upper limb rehabilitation exoskeleton. Technol Health Care 23: 197-202.

96. Xiao F, Gao Y, Wang Y, Zhu Y, Zhao J (2017) Design of a wearable cabledriven upper limb exoskeleton based on epicyclic gear trains structure. Technology and Health Care Preprint (Preprint), pp: 1-9.

97. Malin G (2015) 6-REXOS: Upper Limb Exoskeleton Robot with Improved pHRI Int J Advanced Robot Systems.

98. Badesa FJ, Morales R, Garcia-Aracil N, Sabater JM, Perez-Vidal C (2012) Multimodal Interfaces to Improve Therapeutic Outcomes in Robot-Assisted Rehabilitation. IEEE Transactions on Systems, Man, and Cybernetics, Part C (Applications and Reviews) 42: 1152-1158.

99. Papaleo E, Zollo L, Spedaliere L, Guglielmelli E (2013) Patient-tailored adaptive robotic system for upper-limb rehabilitation. 2013 IEEE International Conference on Robotics and Automation), pp: 3860-3865.

100. Badesa FJ, Morales R, Garcia-Aracil N, Sabater JM, Casals A, et al. (2014) Auto-adaptive robot-aided therapy using machine learning techniques. Computer Methods and Programs in Biomedicine 116: 123-130.

101.Perry JC, Rosen J, Burns S (2007) Upper-limb powered exoskeleton design IEEE/ASME Transactions on Mechatronics 12: 408-417.

102. Rahman MH, Saad M, Kenné JM, Archambault PS (2013) Control of an Exoskeleton Robot Arm with Sliding Mode Exponential Reaching Law. International Journal of Control, Automation, and Systems 11: 92-104.

103. Tsagarakis N, Caldwell D (2003) Development and control of a "soft-actuated" exoskeleton for use in physiotherapy and training. Autonomous Robots 15 : 21-33.

104.Umemura, A, Saito Y, Fujisaki K (2009) A study on power-assisted rehabilitation robot arms operated by patient with upper limb disabilities. IEEE International Conference on Rehabilitation Robotics (ICORR)), pp: 451-456.

105. Garrido J, Yu W, Li X (2016) Modular design and control of an upper limb exoskeleton. J Mech Sci Technol 30: 2265-2271.

106. Liu L, Shi YY, Xie L (2016) A Novel multi-dof exoskeleton robot for upper limb rehabilitation. Journal of Mechanics in Medicine and Biology 16: 1640023.

107. Cui X, Chen W, Jin X, Agrawal SK (2017) Design of a 7-DOF Cable-Driven Arm Exoskeleton (CAREX-7) and a Controller for Dexterous Motion Training or Assistance. IEEE/ASME Transactions on Mechatronics 22: 161-172.

108. Kim H, Kim J (2017) Control of the seven-degree-of-freedom upper limb 
Citation: Islam MR, Spiewak C, Rahman MH, Fareh R (2017) A Brief Review on Robotic Exoskeletons for Upper Extremity Rehabilitation to Find the Gap between Research Porotype and Commercial Type. Adv Robot Autom 6: 177. doi: 10.4172/2168-9695.1000177

exoskeleton for an improved human-robot interface. Journal of the Korean Physical Society 70: 726-734.

109. Tsai BC, Wang WW, Hsu LC, Fu LC, Lai J (2010) An articulated rehabilitation robot for upper limb physiotherapy and training. IEEE/RSJ International Conference on Intelligent Robots and Systems (IROS)), pp: 1470-1475.

110. Yupeng $Y$, Hyung-Soon, $P$, Li-Qun, $Z$ (2009) Developing a whole-arm exoskeleton robot with hand opening and closing mechanism for upper limb stroke rehabilitation. IEEE International Conference on Rehabilitation Robotics: Reaching Users \& the Community (ICORR)), pp: 761-765.

111. Toth A, Fazekas G, Arz G, Jurak M, Horvath M (2005) Passive robotic movement therapy of the spastic hemiparetic arm with REHAROB: report of the first clinical test and the follow-up system improvement. International Conference on Rehabilitation Robotics (ICORR)), pp: 127-130.

112. Kawasaki H, Ito $S$, Ishigure $Y$, Nishimoto $Y$, Aoki T, et al. (2007) Development of a hand motion assist robot for rehabilitation therapy by patient selfmotion control. IEEE 10th International Conference on Rehabilitation Robotics ICORR'07), pp: 257-263.

113. Schiele A, van der Helm F (2006) Kinematic design to improve ergonomics in human machine interaction. IEEE Trans. Neural Syst Rehabil Eng 14: 456-469.

114. Riener R, Guidali M, Keller U, Duschau-Wicke A, Klamroth V, et al. (2011) Transferring Armin to the clinics and industry. Spinal Cord Inj Rehabil 17: 54-59.

115. Pons JL (2008) Wearable robots: biomechatronic exoskeletons. John Wiley \& Sons.

116. Stienen AHA., Hekman EEG, Frans CT, Helm VD, Herman van der Kooij HVD (2009) Self-Aligning Exoskeleton Axes Through Decoupling of Joint Rotations and Translations. IEEE Transactions on Robotics 25: 628-633.

117. Esmaeili, M, Gamage K, Tan E, Campolo D (2011) Ergonomic considerations for anthropomorphic wrist exoskeletons: A simulation study on the effects of joint misalignment. Intelligent Robots and Systems (IROS), pp: 4905-4910.

118. Ball SJ, Brown IE, Scott SH (2007) MEDARM: a rehabilitation robot with 5DOF at the shoulder complex, In: Adv Intelligent Mechatronics, pp: 1-6.

119. Christensen S, Bai S (2017) A Novel Shoulder Mechanism with a Double Parallelogram Linkage for Upper-Body Exoskeletons. Wearable Robotics: Challenges and Trends 16: 51-56.

120. Malosio M, Pedrocchi N, Vicentini F, Tosatti LM (2011) Analysis of ElbowJoints Misalignment in Upper-Limb Exoskeleton. IEEE Int Conf Rehabil Robot 2011:5975393.
121.Lo HS, Xie SQ (2012) Exoskeleton robots for upper-limb rehabilitation: state of the art and future prospects. Medical Engineering \& Physics 34: 261-268.

122. Laschi C, Cianchetti M (2014) Soft Robotics: New Perspectives for Robot Bodyware and Control. Frontiers in Bioengineering and Biotechnology 2: 3.

123. Walha L, Fakhfakh T, Haddar M (2006) Backlash effect on dynamic analysis of a two-stage spur gear system. Journal of Failure Analysis and Prevention 6: 60-68.

124.Sclater N, Chironis NP (2007) Mechanisms and mechanical devices sourcebook. McGraw-Hill.

125.Popov D, Gaponov I, Lee SJ, Ryu JH (2015) Auxilio: Lightweight Soft Upper Extremity Exoskeleton. BioRobotics Lab, School of ME, KOREATECH.

126. Yu W, Rosen J (2010) A novel linear PID controller for an upper limb exoskeleton. Prof. of the 49th IEEE Conference on Decision and Control, pp: 3548-3553.

127.Lawrence D (1988) Impedance control stability properties in common implementations. IEEE International Conference on Robotics and Automation, pp: $1185-1190$

128. Tang Z, Zhang K, Sun S, Gao Z, Zhang L, et al. (2014) An Upper-Limb PowerAssist Exoskeleton Using Proportional Myoelectric Control. Sensors 14: 6677 6694.

129. Kiguchi K, Hayashi Y (2012) An EMG-Based Control for an Upper-Limb Power-Assist Exoskeleton Robot. IEEE Transactions on Systems, Man, and Cybernetics, Part B (Cybernetics) 42: 1064-1071.

130. Bennett AF (1985) Temperature and muscle. Journal of Experimental Biology 115: 333-334.

131. Chennareddy SSR, Agrawal A, Karuppiah A (2017) Corrigendum to \& \#x201C Modular Self-Reconfigurable Robotic Systems: A Survey on Hardware Architectures. J Robot 2017: 1-4.

132. Piña-Martínez E, Roberts R, Rodriguez-Leal E, Flores-Arredondo $\mathrm{JH}$, Soto R (2017) A Novel Exoskeleton for Continuous Monitoring of the Upper-Limb During Gross Motor Rehabilitation. Converging Clinical and Engineering Research on Neurorehabilitation II, pp: 1199-1203.

133. Benitez LM, Tabie M, Will N, Schmidt S, Jordan M, et al. (2013) Exoskeleton Technology in Rehabilitation: Towards an EMG-Based Orthosis System for Upper Limb Neuromotor Rehabilitation. Journal of Robotics 2013: 13. 